\title{
Microbial Metabolism of Tholin
}

\author{
C. R. STOKER \\ NASA Ames Research Center, Moffett Field, California 94035 \\ P. J. BOSTON ${ }^{1}$ \\ National Center for Atmospheric Research, P.O. Box 3000, Boulder, Colorado 80307
}

R. L. MANCINELLI

NASA Ames Research Center, Moffett Field, California 94035

W. SEGAL

Environmental, Population and Organismic Biology, University of Colorado, Boulder, Colorado 80309

AND

B. N. KHARE AND C. SAGAN

Laboratory for Planetary Studies, Cornell University, Ithaca, New York 14853

Received February 8, 1988; revised October 30, 1989

In this paper, we show that a wide variety of common soil bacteria are able to obtain their carbon and energy needs from tholin (a class of complex organic heteropolymers thought to be widely distributed through the solar system; in this case tholin was produced by passage of electrical discharge through a mixture of methane, ammonia, and water vapor). We have isolated aerobic, anaerobic, and facultatively anaerobic bacteria which are able to use tholin as a sole carbon source. Organisms which metabolize tholin represent a variety of bacterial genera including Clostridium, Pseudomonas, Bacillus, Acinetobacter, Paracoccus, Alcaligenes, Micrococcus, Corynebacterium, Aerobacter, Arthrobacter, Flavobacterium, and Actinomyces. Aerobic tholin-using bacteria were first isolated from soils containing unusual or sparse carbon sources. Some of these organisms were found to be facultatively anaerobic. Strictly anaerobic tholin-using bacteria were isolated from both carbon-rich and carbon-poor anaerobic lake muds. In addition, both aerobic and anaerobic tholin-using bacteria were isolated from common soil collected outside the laboratory building. Some, but not all, of the strains that were able to obtain carbon from tholin were also able to obtain their nitrogen requirements from tholin. Bacteria isolated from common soils were tested for their ability to obtain carbon from the water-soluble fraction, the ethanol-soluble fraction, and the water/ethanol-insoluble fraction of the tholin. Of the $3.5 \times 10^{7}$ bacteria isolated per gram of common soils, 1.7 , 0.5 , and $0.2 \%$, respectively, were able to obtain their carbon requirements from the watersoluble fraction, the ethanol-soluble fraction and the water/ethanol-insoluble fraction of the tholin. The palatability of tholins to modern microbes may have implications for the early evolution of microbial life on Earth. Tholins may have formed the base of the food chain for an early heterotrophic biosphere before the evolution of autotrophy on the early

${ }^{1}$ Present address: Complex Systems Research, Inc., 10695 Arapahoe Rd, Lafayette, CO 80026. 
Earth. Where tholins are present on other planets, they could possibly be metabolized by contaminant microorganisms transported to these bodies via spacecraft. Thus, the presence of tholins should be taken into account when evaluating the planetary quarantine requirements for probes to other planets. 1990 Academic Press, Inc.

\section{INTRODUCTION}

The origin of life on Earth is one of the greatest unsolved mysteries in science today. The widely accepted Oparin-Haldane paradigm for the origin of life holds that life arose from abiotically produced organic compounds (Oparin 1924, Haldane 1929). The first life forms were primitive heterotrophic organisms that obtained food and energy from these same abiotically produced organics (Oparin 1924, Haldane 1929, cf. Margulis 1981). This paradigm was supported by the early laboratory experiments of Miller and Urey (Miller 1953, 1955, 1957) who produced prebiotic organic molecules, especially amino and hydroxy acids, from a mixture of methane, ammonia, and water vapor. Their classic experiments formed the foundation for the field of prebiotic chemistry, the experimental study of the origin of life based on laboratory production of organic compounds [for reviews of the multitude of experiments performed see Miller and Orgel (1974), Gabel (1977), and Day (1979)]. Sagan and Khare (1979) proposed the name "tholin" to describe the entire class of complex organic solids produced in such laboratory experiments.

If, as the Oparin-Haldane paradigm implies, tholins supported the food chain for Earth's earliest life forms then they may be able to support presumably more capable modern heterotrophic microorganisms as well. In the present paper, we demonstrate that tholins can be used as a sole source of carbon and nitrogen by a wide variety of heterotrophic soil bacteria.

An important question about the origin of life is whether there are planetary environments other than Earth where life may exist or could survive if transported there. Bacteria are the simplest self-sustaining terrestrial life forms but they are also the most ubiquitous and hardy and they can adapt to the widest variety of conditions. Thus, it is natural to assume that something like them, or at least occupying the same ecological niches, should be present if there is extraterrestrial life. Therefore, it is important to consider what factors might influence the survival of such organisms on other planets. Tholins could be a key nutrient source for such organisms and in fact could be a primary link in the food chains in environments where they are produced. Tholins are produced by a variety of energy sources in reducing or mildly reducing environments that are analogous to common environments in the solar system. For example, tholins have been produced under conditions simulating the atmospheres of the outer planets Jupiter (Khare et al. 1978, 1981, Khare and Sagan 1973), Titan (Khare et al. 1984, 1986), and Uranus and Neptune (Khare et al. 1987) and on the surfaces of icy satellites (Calcagno et al. 1985, Thompson et al. 1987). Although the specific properties of individual tholins depend upon the gas mixtures and energy sources used (Sagan et al. 1984a), the most generic feature is that biologically relevant molecules such as amino acids and their precursor molecules are produced in virtually all of the experiments (cf. Chang et al. 1984).

In this paper, we present laboratory experiments which demonstrate that tholin [produced by sparking an equimolar mixture of methane and ammonia with $2.5 \%$ water vapor (Khare et al. 1981)] is metabolized as a sole source of carbon and energy by a wide variety of terrestrial soil microbes under both aerobic and anaerobic conditions. Some of these organisms are also able to obtain their nitrogen requirements from tholin. 
TABLE I

Amino Acids In SPark Tholin ${ }^{a}$

\begin{tabular}{lccc}
\hline $\begin{array}{c}\text { Amino acid } \\
\text { (in } \mu \text { mole/g) }\end{array}$ & $\begin{array}{c}\text { Free amino acids } \\
\text { in solution }\end{array}$ & $\begin{array}{c}\text { Free and bound } \\
\text { amino acids } \\
\text { in solution } \\
\text { (after hydrolysis) }\end{array}$ & $\begin{array}{c}\text { Free and bound } \\
\text { amino acids } \\
\text { in Tholin powder } \\
\text { (after hydrolysis) }\end{array}$ \\
\hline Asx (Asn, Asp) & $<0.8 \pm 0.3^{b}$ & $34 \pm 15$ & $49 \pm 12$ \\
Glx (Gln, Glu) & $<0.8 \pm 0.3$ & $10 \pm 2$ & $14 \pm 3$ \\
Ser & $<0.8 \pm 0.3$ & $<0.8 \pm 0.3$ & $<0.85 \pm 0.55$ \\
Gly & $12.4 \pm 9.6$ & $250 \pm 65$ & $423 \pm 99$ \\
Arg & $<0.8 \pm 0.3$ & $<0.8 \pm 0.3$ & $<0.85 \pm 0.55$ \\
Thr & $<0.8 \pm 0.3$ & $<0.8 \pm 0.3$ & $<0.85 \pm 0.55$ \\
Ala & $<\mathbf{1 . 0 5} \pm 0.05$ & $21 \pm 3$ & $29 \pm 2$ \\
Tyr & $<0.8 \pm 0.3$ & $1.6 \pm 0.5$ & $5 \pm 3$ \\
Ile & $<0.8 \pm 0.3$ & $1.05 \pm 0.5$ & $1.2 \pm 0.2$ \\
Leu & $<0.8 \pm 0.3$ & $1.5 \pm 1$ & $1.79 \pm 1.49$ \\
Phe & $<0.8 \pm 0.3$ & $1.55 \pm 0.45$ & $3.2 \pm 1.8$ \\
Lys & $<0.8 \pm 0.3$ & $<0.8 \pm 0.3$ & $<0.85 \pm 0.55$ \\
His, Pro, Val ${ }^{c}$ & - & - & - \\
\hline
\end{tabular}

${ }^{a}$ The results represent the averages of two sets of analysis; the probability error shown represents the difference between the two values of amino acid yield and the mean. There are other chemical species present-possibiy including other amino acids besides the 15 used in the standard.

${ }^{b}$ The $<$ indicates the limit of detectability. All values in $\mu$ mole/g of tholin.

${ }^{c}$ There is some absorption in the region where His, Pro, and Val elute but their retention times are far enough off from the standards that their identification is uncertain.

An analysis of the tholin used in these experiments is given in Khare et al. (1981). The atomic composition of this tholin, after exposure to air, is $\mathrm{H}, 5 \% ; \mathrm{C}, 47 \% ; \mathrm{N}, 36 \%$ and $\mathrm{O}, 12 \%$. Pyrolysis gas chromatography/ mass spectrometry of the tholin yields a range of biologically interesting molecules including alkanes, alkenes, abundant nitriles, aromatic hydrocarbons, alkylbenzenes, indenes, indanes, pyrroles, pyridine, and pyrazines (Khare et al. 1981). The tholin is very refractory, requiring $T \sim 900^{\circ} \mathrm{C}$ for $50 \%$ thermal dissociation (Sagan et al. 1984a). Amino acid analysis of the tholin shows that it contains a number of free and bound amino acids (Table I). Tholins produced from other precursor gases including simulated Titanian atmospheres yield an equally rich array of pyrolyzates (Khare et al. 1984) and a variety of racemic amino acids (Sagan and Khare 1971, Khare et al. 1986).

With this range of potential metabolites available it is not surprising that tholins can support microbial life. In fact, it has commonly been assumed that tholins could serve as a substrate for microbial growth. Chemical synthesis experimenters have been careful not to accidentally contaminate their products with bacteria before they could be analyzed. The belief that tholins could serve as a substrate for microbial growth, and that tholins are widespread in extraterrestrial environments, led Apollo investigators to use tholins as a test nutrient medium in attempting to culture organisms from lunar soils (Oyama 1972). However, in spite of the lengthy history of laboratory production of tholins, no systematic study of microbial growth on tholins nor any attempt to characterize the organisms that could use tholins has been previously performed.

In the following section, we describe the experimental methods used to isolate bacteria capable of metabolizing $\mathrm{CH}_{4} / \mathrm{NH}_{3} / \mathrm{H}_{2} \mathrm{O}$ 
tholin and present the results. Section IIA describes the production and analysis of the tholin used in our experiments, Section IIB describes the procedure first used to search for bacteria that could obtain their requirements for carbon and energy from tholin. In this first set of experiments, a wide variety of soil samples were collected and exposed to a range of environmental parameters since we did not know how difficult it would be to find organisms that could utilize tholin. In Section IIC we describe a second set of experiments in which a different and simpler isolation procedure was performed using common soil. Section III contains a discussion of the possible implications of our results as they relate to the origin of life on Earth and the occurrence of life elsewhere in the solar system. Section IV briefly summarizes our conclusions.

\section{EXPERIMENTS}

\section{A. Production and Analysis OF THOLIN}

Tholin was produced by subjecting equimolar amounts of $\mathrm{CH}_{4}$ and $\mathrm{NH}_{3}$ along with approximately $2.5 \%$ water vapor to a spark discharge produced by a high-frequency Tesla coil. A detailed description of the preparation of the tholin is given in Khare et al. (1981). The tholin has been analyzed using mass spectroscopy, thermogravimetric analysis, and combined vacuum pyrolysis gas chromatography/mass spectrometry (GC/MS). The results of these analyses are published in Khare et al. (1981).

We examined the tholin for free amino acids in solution, free and bound amino acids in solution (after hydrolysis), and free and bound amino acids in tholin powder (after hydrolysis). The search was limited to 15 protein non-S-containing amino acids. A solution was prepared by suspending $6.4 \mathrm{mg}$ of spark tholin in $3.5 \mathrm{ml} \mathrm{HPLC}$-grade (MilliQ) water. It was autoclaved for $15 \mathrm{~min}$ at $121^{\circ} \mathrm{C}$ and cooled slowly. After centrifugation, $2 \mathrm{ml}$ of supernatant was measured into another tube-leaving behind the remaining liquid and the insoluble material-and kept under vacuum to dry at $\sim 55^{\circ} \mathrm{C}$. It was then resuspended in $200 \mu \mathrm{l}$ HPLC-grade water (Milli-Q).

Fifty microliters of this solution was transferred into another container and redried to determine free amino acids in solution by the Waters Pico-Tag HPLC method (Cohen et al. 1986). Of the remaining $150 \mu \mathrm{l}$ solution, $50 \mu \mathrm{l}$ was transferred into a hydrolysis vial with a Teflon cap and evaporated to dryness. The sample was hydrolyzed with $6 \mathrm{~N} \mathrm{HCl}$ at $150 \pm 1{ }^{\circ} \mathrm{C}$ under argon for 90 min, and then cooled to room temperature. $\mathrm{HCl}$ was removed by subjecting it to vacuum, adding $20 \mu l$ redry reagent $[2 / 2 / 1$ $(\mathrm{v} / \mathrm{v} / \mathrm{v})$ ethyl alcohol/water/triethylamine], evacuating to $\sim 1$ Torr, repeating the process with the addition of redry reagent, and then evacuating to dryness. Finally, $50 \mu \mathrm{l}$ of Edman degradation reagent was added for the determination of combined free and bound amino acids in the solution by the same HPLC method.

The remaining liquid/solid mix was centrifuged and the supernatant removed. It was rinsed twice with $0.5 \mathrm{ml}$ HPLC-grade water (Milli-Q). As much of the supernatant as possible was removed each time. The solid was then evaporated to dryness under vacuum and found to have a mass of $-4.0 \mathrm{mg} ; 2.6 \mathrm{mg}$ of this solid was then hydrolyzed in $6 \mathrm{~N} \mathrm{HCl}$ at $150^{\circ} \mathrm{C}$ for 90 min. Amino acids were determined by following the same procedure described above. By adding the amino acids calculated for hydrolyzed $3.5 \mathrm{ml}$ supernatant to the amino acids calculated for hydrolyzed $\sim 4.0 \mathrm{mg}$ solid left behind after removing the supernatant, the total amount of free and bound amino acids in the tholin powder was determined. The entire analysis was repeated on a different sample of tholin to check the reproducibility of the amino acid yield. Table I shows the results of the analysis for free amino acids in solution, free + bound amino acids in solution (after hydrolysis), and free + 
bound amino acids in the tholin powder (after hydrolysis).

\section{B. ISOLATION OF THOLIN-USING \\ Organisms From UnUSUAL SoIls}

\section{Procedure}

For the first isolation experiments, we collected soil samples from a variety of environments which we felt might contain organisms likely to utilize unusual or sparse carbon sources. This range of soils were tested because we did not know how difficult it would be to find organisms that could use tholin and we thought this would improve our chance of success.

We tested tar sands from Vernal, Utah, because we expected them to contain organisms capable of breaking down the complex hydrocarbons found in tholins. We also tested alpine soils from carbon-poor environments because they contain organisms that get by on very sparse nutrients in case very little of the tholin could actually be metabolized. We tested anaerobic microorganisms from both an extremely organicrich and an organic-poor environment in case organisms with either preference could metabolize the tholin. The experiments were performed in five phases. First, we collected a variety of soil samples to search for possible tholin-using microbes in nature. Second, we enriched the samples with tholin to selectively encourage growth of species able to use tholin. Third, we isolated promising organisms from the enrichments and grew them in pure culture. Fourth, we screened these pure strains rigorously for their ability to grow on tholin as the only carbon source. Fifth, we identified tholinusing strains to the genus level. Figure 1 illustrates an overview of the experimental sequence. Each of these phases is described in greater detail below. We were only interested in strictly heterotrophic organisms. All incubations were carried out in the dark to prevent photoautotrophic organisms from growing.

Phase I. We prepared an aqueous solution of the tholin $(0.1 \mathrm{~g} / \mathrm{ml}$ concentration) by placing solid tholin in triply distilled water and autoclaving the mixture at $120^{\circ} \mathrm{C}$ for $15 \mathrm{~min}$. After this treatment, approximately 80-85\% (determined gravimetrically) went into aqueous solution. The insoluble fraction remained as small spheroids at the bottom of the water-tholin solution. The insoluble fraction was not separated from the stock so that both soluble and insoluble components were used in the experiments. Tholin-containing media at various concentrations were prepared from this stock. In addition to tholin, all organisms were provided with a basal mineral salts medium prepared with a broad spectrum of trace minerals.

We collected soil and sediment samples from both aerobic and anaerobic environments. Aerobic samples of tar sands (silica grains covered with a rich coating of complex hydrocarbons) were collected from a tar-sand pit in Vernal, Utah. In addition, we collected several aerobic samples of carbonpoor alpine soils from 3000 - to 3500 -m-altitude barren sites in Rocky Mountain National Park. Anaerobic sediments were collected during the winter from frozen mud flats of two shallow lakes near Boulder, Colorado. One lake is a highly eutrophied environment receiving runoff from surrounding cow pastures. The other is a nutrient-poor lake at approximately $2500 \mathrm{~m}$ altitude.

Soil samples were collected using sterile soil corers fitted into large $(200-\mathrm{mm})$ test tubes. Aerobic samples were cored to a depth of 4 or $5 \mathrm{~cm}$. Material was retained in the corers and transported to the laboratory in these devices. Anaerobic samples of frozen mud were cored to a depth of 7 or $8 \mathrm{~cm}$ and immediately introduced into jars containing liquid media combined with one of three reducing agents (sodium thioglycolate, $\mathrm{FeS}_{2}$, or $\mathrm{Na}_{2} \mathrm{~S}$ ). The three reducing agents were used because each of them is known to be toxic to certain species of bacteria (Costilow 1981) and we did not want to risk killing potential tholin-using organisms with a particular reagent. 


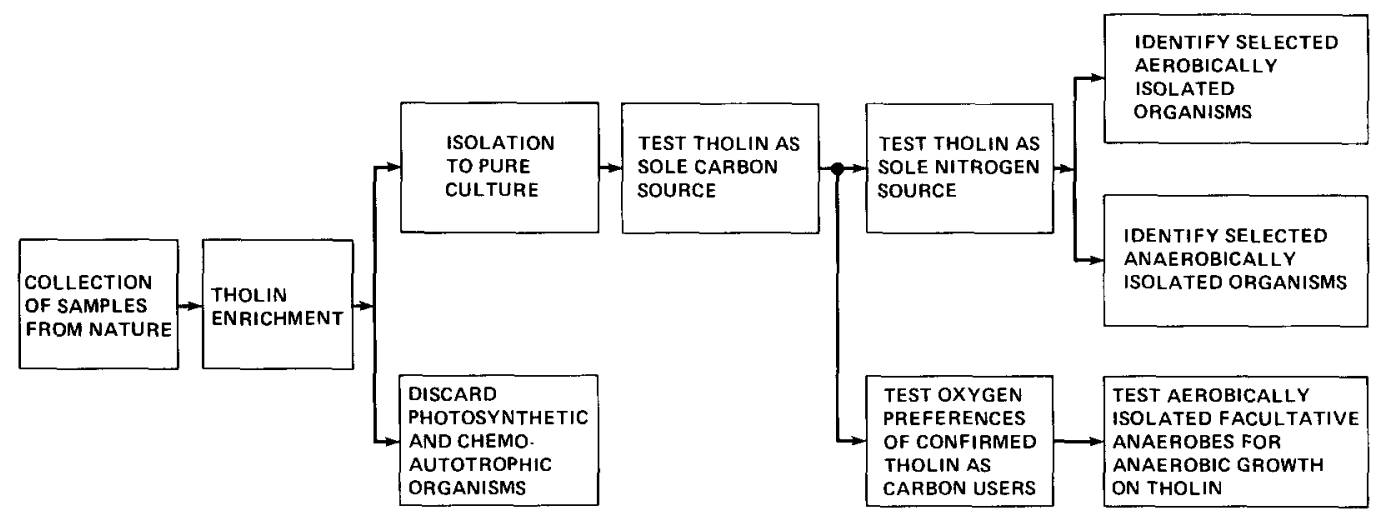

FIG. 1. Schematic of procedure used in initial experiments to isolate tholin-using organisms.

Phase 2. We first treated samples to a tholin-enrichment procedure. For aerobic soil samples, this consisted of placing $0.5-\mathrm{g}$ soil aliquots in flasks containing the liquid basal salts medium (see Appendix) and tholin at $5.0 \mathrm{~g} \mathrm{liter}^{-1}$ concentration. Control flasks were identical but without tholin. Six sets of all samples and controls were prepared and incubated at each of three temperatures-4, 22, and $37^{\circ} \mathrm{C}$-at a $\mathrm{pH}$ of 7.0 . The samples were incubated on shakers for 10 days to 4 weeks depending upon rapidity of growth as manifested by turbidity of the medium.

The anaerobic samples were subjected to a similar tholin-enrichment procedure. Upon return to the laboratory, the anaerobic field collection jars were swirled on a shaker for $30 \mathrm{~min}$ to loosen organisms from soil particles and suspend them in the liquid medium. The jars were then placed in an anaerobic chamber which held an $\mathrm{N}_{2}$ atmosphere maintained at a slight positive pressure to exclude outside air. We prepared two sets of four duplicate flasks, four containing tholin and four controls without tholin. The media in the flasks consisted of liquid basal salts medium combined with one of the three reducing agents. One additional flask was prepared without a reducing agent but rather was allowed to equilibrate with the $\mathrm{N}_{2}$ atmosphere in the anaerobic chamber for $24 \mathrm{hr}$ before it was inoculated. We inoculated these flasks with samples withdrawn via syringe from the field collection jars and incubated them in the anaerobic chamber for 2 to 5 weeks depending upon visible growth. We initiated phase 3 after significant visible growth was observed.

Phase 3. In phase 3, we isolated colonies of organisms from the tholin-enrichment flasks using plates made with the basal salts medium and tholin concentrations of $\mathbf{0 . 3 3}$, $0.5,1.0,5.0$, and $10.0 \mathrm{~g} \mathrm{liter}^{-1}$. We used silica gel [BBL ultrapure silica powder; see Funk and Krulwich (1964) for the preparation] as a solidifying agent rather than agar since some organisms can metabolize agar (Krieg and Gerhardt 1981). Silica gel contains no carbon or nitrogen. At 2- to 5-day intervals, liquid was withdrawn from the enrichment flasks, serially diluted to concentrations ranging over five orders of magnitude, and spread onto plates to allow growth of colonies from single organisms. This is a common method of isolating strains of bacteria (Koch 1981).

We determined growth by visual inspection. This was adequate because we were interested only in answering the first-order question of whether or not growth occurred on tholin, not in obtaining a quantitative measure of the growth.

We used two types of control plates for the isolation procedure. Negative control "silica gel" plates were identical to the ex- 
perimental plates with the exception that tholin was omitted and thus the medium contained no carbon. Colonies which grew on negative control plates were considered to be deriving carbon from other sources (obtaining carbon from atmospheric $\mathrm{CO}_{2}$ or another gaseous $\mathrm{C}_{1}$ compound) or crossfeeding, that is, using other organisms or cell debris as carbon sources. We removed these strains from subsequent screenings. A second type of control plate was made from extracts of the soil or sediments from which the organisms originated. We used these soil control plates to compare colony morphology and growth rates on native material with those experienced on tholin using qualitative criteria such as the time to appearance of first colonies, overall appearance of colonies, and terminal size of colonies. Although we looked for evidence of inhibition of growth on tholin, most strains grew equally well on tholin and native material.

After we screened the pure cultures of organisms for growth on tholin, they were transferred to retaining tubes containing soil, sediment, or tar-sands extract (in a semisolid form) appropriate to the original source of a given strain. We had only small amounts of tholin and could not waste any on maintenance media. More importantly, we also wished to avoid any changes in the organisms which might result from prolonged growth on tholin. For anaerobes, we placed a sterile mineral oil layer on top of the medium in the retaining tubes to protect them from stray oxygen molecules which are introduced with each access to the chamber and are only scavenged by the catalyst system over a finite period of time.

Phase 4. In this phase of the experiments, we challenged all candidate tholin-using strains to grow on tholin medium as sole carbon source a second time. This was done to ensure that the colonies were pure cultures of single species and to make certain that the organisms were using tholin rather than cross-feeding to obtain carbon. Organisms were introduced into liquid media prepared as in phase 2. Duplicate control sets without tholin were incubated both in dark and in the light to check for chemoautotrophic and photoautotrophic growth.

Phase 5. Tholin-using organisms were identified to the genus level using tests from Bergey's Manual of Determinative Bacteriology (Buchannan and Gibbons 1974).

\section{Results}

Tholin as sole carbon source. We categorized the initial isolates from phase 3 experiments as likely tholin-using heterotrophs, facultative heterotrophs, or autotrophs (either photoautotrophic or chemoautotrophic). Of the initial 540 aerobic isolates, almost one-third (185) showed small amounts of growth on the carbon-free controls. These strains were discarded. The remaining 355 isolates appeared to be strictly heterotrophic under the experimental conditions.

Twenty-two anaerobic isolates were obtained from phase 3 experiments. Of these, none showed growth on the tholin-free controls. Interestingly, none of the tholin users preferred the 4 or $37^{\circ} \mathrm{C}$ incubation temperatures. Many grew marginally at these temperatures although they all grew better at $22^{\circ} \mathrm{C}$.

Table II shows the isolates identified including Actinomyces and several strains of Clostridium, Pseudomonas, Bacillus, Acinetobacter, Paracoccus, and Alcaligenes. One characteristic common to most of these genera is their ability to utilize a wide variety of carbon substrates (Buchannan and Gibbons 1974) ranging from simple organic acids and carbohydrates to high-molecularweight carbon compounds such as plastics and other polymeric hydrocarbons. As shown below, some, but not all, of the aerobes tested from each genus were able to metabolize tholin anaerobically as well as aerobically.

Aerobic vs anaerobic use of tholin. We next tested all aerobic tholin-using organisms for their ability to grow anaerobically. We produced test media with sodium thioglycolate added as a reducing agent (Ger- 
TABLE II

Genera Isolated from Unusual SoIls on Tholin Medium

\begin{tabular}{|c|c|c|c|c|c|}
\hline Genus & $\begin{array}{l}\text { Number } \\
\text { of isolates } \\
\text { identified }^{a}\end{array}$ & $\begin{array}{c}\text { Strict } \\
\text { aerobes }^{b}\end{array}$ & $\begin{array}{l}\text { Facultative } \\
\text { anaerobes }^{c}\end{array}$ & $\begin{array}{c}\text { Strict } \\
\text { anaerobes }^{d}\end{array}$ & $\begin{array}{c}\text { Nitrogen from } \\
\text { tholin }^{e}\end{array}$ \\
\hline Clostridium & 12 & $\mathbf{0}$ & - & 12 & 4 (of 6 tested) \\
\hline Pseudomonas & 46 & 4 & 3 (of 8 tested) & - & 5 (of 11 tested) \\
\hline Bacillus & 7 & 7 & - & - & I(of 4 tested) \\
\hline Acinetobacter & 3 & 2 & - & - & 0 (of 3 tested) \\
\hline Actinomyces & 6 & - & 2 (of 3 tested) & - & 2(of 3 tested) \\
\hline Paracoccus & 2 & - & 2 (of 2 tested) & - & Not tested \\
\hline Alcaligenes & 2 & 1 & - & - & Not tested \\
\hline
\end{tabular}

\footnotetext{
${ }^{a}$ Identification to the genus level of 78 of 377 tholin-metabolizing isolates shows a predominance of Pseudomonas.

${ }^{b}$ Organisms capable of growing only in the presence of oxygen.

${ }^{c}$ Organisms capable of aerobic or anaerobic growth on tholin.

${ }^{d}$ Organisms isolated from anaerobic environment capable of anaerobic growth on tholin.

${ }^{e}$ Organisms capable of using tholin as a sole nitrogen source as well as a sole carbon source.
}

hardt 1981) along with an oxygen-sensitive dye which changed color when the medium was reduced. Filter-sterilized glucose $(0.1 \mathrm{~g}$ liter $^{-1}$ ) was used as a carbon source. Organisms were stab inoculated into small test tubes of the semiliquid ( $0.1 \%$ agar) medium. After inoculation, we placed a 1-cm-thick layer of sterile mineral oil on top of the medium in the tube to retard diffusion of oxygen. Of the 355 organisms tested, 59 grew anaerobically, indicating that they were facultative anaerobes. We then tested 15 of these 59 facultative anaerobes for growth with tholin as a carbon source at tholin concentrations of 1.0 and $5.0 \mathrm{~g} \mathrm{liter}{ }^{-1}$. Eight of these were able to grow anaerobically with tholin as the only carbon source. The 1.0 $\mathrm{g}$ liter ${ }^{-1}$ tholin tubes exhibited slightly less growth than the $5.0 \mathrm{~g}$ liter $^{-1}$ tubes, as expected.

Sole nitrogen source experiments. We tested 20 tholin-metabolizing isolates from the aerobic series and 6 from the anaerobic series to determine whether they could obtain their nitrogen requirements from tholin. For these experiments, $1.0 \mathrm{~g} \mathrm{liter}^{-1}$ filtersterilized glucose was added as a carbon source. Thus, these organisms were chal- lenged to obtain their nitrogen requirements but not their carbon requirements from tholin. First, each organism was cultured on a nitrogen-free basal salts medium with glucose as carbon source. Of the organisms tested, 12 out of 20 of the aerobes and 2 out of 6 of the anaerobes were able to grow on a nitrogen-free medium with visible growth showing after 10 days to 8 weeks. We presumed that these strains were capable of fixing atmospheric nitrogen and discarded them. We then tested whether the remaining organisms were using tholin as a sole source of nitrogen. Of the 8 remaining aerobic strains that were not nitrogen fixers, 7 grew on the tholin-containing, otherwise nitrogen-free medium. The 4 anaerobic strains were all able to grow on tholin-containing, otherwise nitrogen-free medium. Hence, 7 of the 8 aerobic and all of the anaerobic nonnitrogen-fixing strains were able to obtain their nitrogen requirements from the tholin.

\section{Isolation of THOLIN-Using ORGANISMS FROM COMMON SOILS}

The initial isolation of tholin-using organisms described above showed that many species of bacteria could use tholin to obtain 
their carbon and nitrogen requirements. Furthermore, the fact that such a wide range of genera were identified suggested that the ability to metabolize tholin was not rare or unique. In fact, the results implied that the tholin users were common soil microbes. To verify this hypothesis, we performed a second set of experiments to isolate organisms from common soil which could use tholin as their sole carbon source. In addition, these experiments tested whether bacteria could utilize the water-insoluble fraction of tholin. Part of this fraction is soluble in ethanol and part is insoluble in either water or ethanol. We found organisms that could obtain carbon from each of these fractions of the tholin.

\section{Procedure}

We prepared three types of tholin media as follows: We first extracted the water-soluble portion of the tholin by placing $4 \mathrm{~g}$ of tholin along with $100 \mathrm{ml}$ of deionized distilled water in a soxhlet extractor for $6 \mathrm{hr}$. The remaining water-insoluble residue was then extracted with $100 \mathrm{ml}$ of absolute ethanol. The residue remaining after these two extractions was insoluble in either water or ethanol. Each of these three tholin fractions was added to a sterile mineral salts solution consisting of distilled $\mathrm{H}_{2} \mathrm{O}, 1$ liter; $\mathrm{K}_{2} \mathrm{HPO}_{4}$, $1.2 \mathrm{~g} ; \mathrm{NaNO}_{3}, 0.5 \mathrm{~g} ; \mathrm{NH}_{4} \mathrm{Cl}, 0.5 \mathrm{~g}$; $\mathrm{Fe}_{2}\left(\mathrm{SO}_{4}\right) 3 \cdot \mathrm{H}_{2} \mathrm{O}, 0.01 \mathrm{~g} ; \mathrm{KH}_{2} \mathrm{PO}_{4}, 0.14 \mathrm{~g}$; $\mathrm{MgSO}_{4}, 0.1 \mathrm{~g}$. We prepared both liquid media and agar plates from the three tholin fractions and the mineral salts solution. Agar was now used for the experiments because the results of the first experiments (Section IIB) indicated that agar-free plates were not needed. However, as an extra precaution, we tested to make sure putative tholin-using organisms could not metabolize agar. To make liquid media, $25 \mathrm{ml}$ of the water-soluble fraction of tholin was added per liter of mineral salts solution. For the ethanol-soluble fraction, $100 \mathrm{ml}$ of the ethanol extract was first concentrated to $10 \mathrm{ml}$ by evaporation. One milliliter of this concentrate was added per liter of mineral salts solution. Liquid media for the water/ethanol-insoluble tholin fraction was prepared by placing insoluble tholin particles (the residue remaining after performing water and ethanol extractions on the tholin) in $100 \mathrm{ml}$ of the mineral salts medium. One gram of the water/ethanol-insoluble tholin fraction was added per liter of mineral salts solution. In addition, we added ten 3 -mm glass beads to each of the flasks containing the water/ ethanol-insoluble fraction to help break up and expose the insoluble particles to bacterial action. The flasks were agitated during incubation.

We prepared agar media using the same composition as the liquid media except that $20 \mathrm{~g}$ of agar was added per liter of solution. Agar plates containing water/ethanol-insoluble tholin were prepared by suspending 0.1 $\mathrm{g}$ of the insoluble particles in $100 \mathrm{ml}$ of water and spreading $0.5 \mathrm{ml}$ of this suspension over the top of already hardened mineral salts agar plates with a glass spreader.

We isolated tholin-using organisms from common soil collected from near the laboratory building. We selected a $1-\mathrm{m}^{2}$ test plot and divided it into 100 equal $10-\mathrm{cm}^{2}$ subplots. This technique was used to determine if differences in results were observed for different subplots. The soil within this plot was a typical bare clay ground within a shrubby area. During the spring of the year, cores from the top $15 \mathrm{~cm}$ of soil $(5 \mathrm{~cm}$ diameter $\times 15 \mathrm{~cm}$ deep) were collected from 6 of the 100 subplots, placed into sterile containers, and brought into the laboratory. A 1-g portion of each sample was suspended in 100 $\mathrm{ml}$ of sterile saline $(0.85 \% \mathrm{NaCl})$. Several 10 fold serial dilutions were made from this suspension by withdrawing $1-\mathrm{ml}$ aliquots from each of a succession of soil-plus-saline mixtures and adding them to $100 \mathrm{ml}$ of fresh sterile saline.

After preparing the soil dilutions, we placed $0.1-\mathrm{ml}$ aliquots from each of the soil dilutions into $100 \mathrm{ml}$ of three types of liquid culture media consisting of mineral salts and either the water-soluble tholin fraction, the ethanol-soluble tholin fraction, or the 
water/ethanol-insoluble fraction. All incubations were carried out on an aerobic and an anaerobic set of cultures. The anaerobic cultures were incubated inside BBL anaerobic jars (Gerhardt 1981). The inoculated liquid media were incubated and agitated in a shaker at a constant rate for 7 days at $22^{\circ} \mathrm{C}$. After 7 days incubation, a $0.1-\mathrm{ml}$ aliquot from each liquid culture medium was placed into a flask of fresh sterile medium of the same type and incubated for 7 more days at $22^{\circ} \mathrm{C}$.

In addition to liquid media, a set of agar plates, made from each of the three tholin fractions as described above, were inoculated with $0.1-\mathrm{ml}$ aliquots from each of the soil dilutions. The plates were incubated aerobically and anaerobically at $22^{\circ} \mathrm{C}$ for 7 days. After 7 days, we counted the colonies on the plates. We also made replica plates ${ }^{2}$ from each of the countable plates (those having 10-300 colonies). The replica plates were incubated for 7 more days at $22^{\circ} \mathrm{C}$. After incubation, we counted the colonies and compared the growth pattern on the replica plates to that on the original plates to verify that the colonies were using tholin as a carbon source and not using carbon from soil that was carried over in the dilutions. In addition, to determine numbers of bacteria capable of chemoautotrophic or photoautotrophic growth or agar metabolism, we prepared plates with media that contained no carbon substrate and used them to make replica plates from the tholin plates. These control replica plates were incubated as described above. We then discarded colonies which grew on the control replica plates.

In addition to the tholin-containing plates, we also prepared half-strength nutrient agar plates by dissolving nutrient broth $\left(4 \mathrm{~g} \mathrm{liter}^{-1}\right)$ into a solution containing agar $\left(15 \mathrm{~g} \mathrm{liter}^{-1}\right)$. These nutrient agar plates were used to determine total numbers of organisms per gram dry weight of

\footnotetext{
${ }^{2}$ Replica plating is a technique which allows inoculation of additional plates with the exact pattern of colonies on the original plate.
}

soil (e.g., Gerhardt 1981, pp. 350-358). Using the spread-plate technique, the nutrient agar plates were inoculated with 0.1$\mathrm{ml}$ aliquots from each of the soil dilutions and incubated as described above.

Since ethanol is toxic to some bacteria and can be used by others as a carbon source, we made control flasks and plates to determine if any of the soil isolates were able to use ethanol as a sole carbon-source. In addition, nutrient broth ( $4 \mathrm{~g} \mathrm{liter}^{-1}$ ) flasks and agar plates containing an amount of ethanol equivalent to the test flasks and plates were inoculated with soil dilutions to determine if this small amount of ethanol was toxic to any of the soil bacteria. Ethanol was not toxic in the small quantities used, and no bacteria capable of using it as a sole carbonsource were isolated.

\section{Results}

After incubation, we randomly selected $25 \%$ of the colonies that were capable of using each tholin-fraction and identified the bacteria in each to the genus level using criteria outlined in Bergey's Manual of Determinative Bacteriology (Buchannan and Gibbons 1974). Tables III, IV, and V list the bacterial genera isolated per gram dry weight of soil which were able to metab-

\section{TABLE III}

BACTERIAL GENERA AND NUMBER ISOlATEd From Common Soll That Can Use the Water-Soluble Fraction of Tholin as a Sole Carbon Source

\begin{tabular}{lr}
\hline \multicolumn{1}{c}{ Genus } & $\begin{array}{c}\text { Number of organisms } \\
\text { per gram dry wt soil }\end{array}$ \\
\hline Pseudomonas & $21 \pm 3 \times 10^{4}$ \\
Bacillus & $18 \pm 5 \times 10^{4}$ \\
Acinetobacter & $5 \pm 1 \times 10^{4}$ \\
Paracoccus & $8 \pm 1 \times 10^{4}$ \\
Micrococcus & $1 \pm 1 \times 10^{4}$ \\
Corynebacterium & $2 \pm 1 \times 10^{4}$ \\
Aerobacter & $1 \pm 1 \times 10^{4}$ \\
Clostridium & $2 \pm 1 \times 10^{4}$ \\
\hline
\end{tabular}

\footnotetext{
${ }^{a}$ Reported as the mean \pm standard deviation of number of organisms isolated on tholin plates.
} 
TABLE IV

BaCterial GENERA AND NUMBER ISOLATED FROM Common Soll That Can Use the EthanolSoluble Fraction of Tholin as a Sole Carbon SOURCE

\begin{tabular}{lr}
\hline \multicolumn{1}{c}{ Genus } & $\begin{array}{c}\text { Number of organisms } \\
\text { per gram dry wt soil }\end{array}$ \\
\hline Pseudomonas & $7 \pm 1 \times 10^{4}$ \\
Bacillus & $8 \pm 1 \times 10^{4}$ \\
Paracoccus & $1 \pm 1 \times 10^{4}$ \\
Clostridium & $1 \pm 1 \times 10^{4}$ \\
\hline
\end{tabular}

${ }^{a}$ Reported as the mean \pm standard deviation of number of organisms isolated on tholin plates.

olize the water-soluble, ethanol-soluble, and water/ethanol-insoluble fractions of tholin, respectively. Table VI shows all bacterial genera isolated from nutrient agar, reflecting the total population of identified organisms in the soil. The predominant soil bacterial genera isolated included Bacillus, Pseudomonas, and Acinetobacter. A total of $3.5 \times 10^{7}$ organisms were isolated per gram dry weight of soil. Of these, we found that $1.7 \%$ of the total identified bacteria count could utilize the water-soluble fraction of tholin, $0.5 \%$ could utilize the ethanol-

\section{TABLE V}

Bacterial Genera and Number Isolated from Common Soll That Can Use the Water/EthanolInsoluble Fraction of Tholin as Sole Carbon SOURCE

\begin{tabular}{lr}
\hline \multicolumn{1}{c}{ Genus } & $\begin{array}{c}\text { Number of organisms } \\
\text { per gram dry wt soil }\end{array}$ \\
\hline Pseudomonas & $27 \pm 5 \times 10^{3}$ \\
Bacillus & $15 \pm 2 \times 10^{3}$ \\
Micrococcus & $1 \pm 1 \times 10^{3}$ \\
Aerobacter & $3 \pm 1 \times 10^{3}$ \\
Arthrobacter & $2 \pm 1 \times 10^{3}$ \\
Flavobacterium & $5 \pm 1 \times 10^{3}$ \\
Acinetobacter & $12 \pm 2 \times 10^{3}$ \\
Clostridium & $1 \pm 1 \times 10^{3}$ \\
\hline
\end{tabular}

\footnotetext{
${ }^{a}$ Reported as the mean \pm standard deviation of num-
} ber of organisms isolated on tholin plates.
TABLE VI

Bacterial Genera and NUMBER ISOlated from Common Soll Using Dilute (50\% Strength) Nutrient Agar

\begin{tabular}{lr}
\hline \multicolumn{1}{c}{ Genus } & $\begin{array}{c}\text { Number of organisms } \\
\text { per gram dry wt soil }\end{array}$ \\
\hline Pseudomonas & $95 \pm 10 \times 10^{5}$ \\
Bacillus & $82 \pm 12 \times 10^{5}$ \\
Micrococcus & $3 \pm 1 \times 10^{5}$ \\
Aerobacter & $4 \pm 1 \times 10^{5}$ \\
Arthrobacter & $21 \pm 5 \times 10^{5}$ \\
Flavobacterium & $35 \pm 8 \times 10^{5}$ \\
Paracoccus & $27 \pm 8 \times 10^{5}$ \\
Acinetobacter & $18 \pm 4 \times 10^{5}$ \\
Clostridium & $10 \pm 2 \times 10^{5}$ \\
Actinomyces & $52 \pm 15 \times 10^{5}$ \\
Corynebacterium & $3 \pm 1 \times 10^{5}$ \\
\hline
\end{tabular}

" Reported as the mean \pm standard deviation of number of organisms isolated on tholin plates.

soluble fraction, and $0.2 \%$ could utilize the water/ethanol-insoluble fraction.

\section{DISCUSSION}

\section{A. IMPLICATIONS FOR THE ORIGIN OF LIFE ON EARTH}

The Oparin-Haldane paradigm for the origin of life explicitly states that the first organisms were heterotrophs that used prebiological organic matter as their primary nutrient source. The results of our experiments lend credence to this hypothesis, particularly since tholins are produced so readily in the laboratory and appear to be palatable to such a wide range of modern heterotrophic bacteria. However, it should be noted that the organisms identified as tholin users are modern and may bear little resemblance to their ancient counterparts. We can only speculate that tholins may have been palatable to ancient heterotrophs as well.

Tholins are produced in strongly reduced mixtures where there is an excess of hydrogen or the presence of reduced gases such as methane and ammonia. Organic compounds can still be synthesized in mildly reducing 
gas mixtures (composed of carbon monoxide or carbon dioxide, nitrogen, hydrogen, and water) but a more limited variety of compounds are produced and the energetic efficiency of production is low compared to strongly reduced mixtures (see Chang et al. 1984). Organic compounds are also produced, but in much lower yields, by either ultraviolet light or electric discharge in neutral gas mixtures [e.g., $\mathrm{CO}_{2}, \mathrm{~N}_{2}$ and $\mathrm{H}_{2} \mathrm{O}$, e.g., Stribling and Miller (1987)]. Because of the lack of geological evidence from the first 0.5 billion years of Earth's history and the theoretical uncertainties about the thermal history of the Earth's formation, the composition of the Earth's early atmosphere is unknown. Possible compositions range from a strongly reducing atmosphere containing significant $\mathrm{CH}_{4}$ and $\mathrm{NH}_{3}$ to a weakly reducing or neutral atmosphere composed of $\mathrm{CO}, \mathrm{CO}_{2}$, and $\mathrm{N}_{2}$ (e.g., Chang et al. 1984). Even if the initial state of the atmosphere was reducing, a neutral atmosphere would have evolved rather quickly. Thus, the supply of tholin compounds produced in situ in the Earth's atmosphere could possibly have supported a heterotrophic biosphere for a brief period after the origin of life, but these compounds would have become increasingly scarce as the atmosphere became more oxidized.

Another potential source of organic compounds needed to sustain a primitive heterotrophic biosphere may have been brought in as a component of meteorites and comets that impacted Earth during the late phase of accretion. Recent spacecraft encounters with Comet Halley show that the comet has a dark mantle (Keller et al. 1986) which is presumably rich in organic material. Giotto experiments also found evidence for chain molecules enriched in carbon, hydrogen, and oxygen, presumably derived from organic polymers (Mitchell et al. 1987, Huebner 1987). Thus, a significant fraction of a comet's mass may be organic carbon. The carbonaceous chondrite meteorites are about $1.5 \%$ organic carbon (Hayes 1967). As comets and meteorites impacted Earth, at least some of this organic material may have reached the Earth's surface unaltered by impact heating. The origin of life occurred between 4.5 and 3.5 billion years ago. During this time period, the impact rate of material declined by several orders of magnitude (Wetherill 1977). As the accretion rate decreased, the supply of potential nutrients provided to a heterotrophic biosphere must also have decreased. Neither in situ production from the primitive atmosphere nor meteoritic/cometary deposition of tholins would have been sufficient to supply the needs of a heterotrophic biosphere indefinitely (Boston and Stoker 1982).

The oldest known evidence of early life is fossilized stromatolite beds that date from 3.5 billion years ago (Schopf and Walter 1984). Modern stromatolites, which closely resemble their ancient counterparts, are formed by sophisticated photoautotrophic communities of microbes. Thus, the development of autotrophy probably occurred quite early. In fact, the increasing scarcity of tholins may have been a strong evolutionary driver for the early development of autotrophy.

\section{B. Implications for Planetary CONTAMINATION}

In our experiments, we have shown that bacteria can metabolize a tholin synthesized by sparking $\mathrm{CH}_{4} / \mathrm{NH}_{3} / \mathrm{H}_{2} \mathrm{O}$ mixtures. Tholins produced in real planetary environments will not be identical to this tholin but, provided net conditions are reducing, they should share many biologically relevant features. For example, amino acids and other biologically important compounds are found in tholins made under conditions that simulate Titan (Khare et al. 1986) and Jupiter (Khare et al. 1978). The fact that bacteria can grow on tholins should be taken into account when evaluating the possibility that bacteria could grow in extraterrestrial environments. This evaluation is important for two reasons: first, to assess the potential for contaminating an extraterrestrial environment by unsterilized spacecraft probes, and 
second, to identify possible environments in which it might be fruitful to search for extraterrestrial life forms. A number of potential ecological niches for bacterial growth on tholins may exist on the outer planets and their satellites. Some examples are discussed below.

\section{Titan}

Tholins may be a component of the thick haze that surrounds Titan. Titan tholin has been produced in laboratory simulations by subjecting a Titan-analog gas mixture to electric discharge (Khare et al. 1984). The optical properties of the Titan tholin can account for Earth-orbital ultraviolet and ground-based visible spectroscopy of Titan (Sagan et al. 1984b, 1985, McKay et al. 1989) as well as Voyager measurements of the infrared continuum (Thompson and Sagan, 1984) and limb darkening in the visible (Squyres et al. 1984, Thompson et al. 1984). Based on production rates for tholin on Titan, Sagan and Thompson (1984) estimate that from $100 \mathrm{~m}$ to several kilometers of tholin could have accumulated on the surface of Titan over geologic time.

It seems likely that bacteria could metabolize Titan tholin although this should be explicitly tested in the laboratory. Titan tholin is produced from a different gas composition than the tholin we used in this study but both tholins have similar breakdown and hydrolysis products including amino acids (Khare et al. 1981, 1986). However, the surface of Titan at $95^{\circ} \mathrm{K}$ (Lindal et al. 1983) is far too cold to allow bacterial growth unless there are warmer areas such as geothermal vents. Geothermal activity on Titan is thought to be unlikely since there is little tidal heating (Reynolds et al. 1987), but the resurfacing of other Saturnian satellites such as Enceladus also has no ready tidal explanation. Episodic tectonic and impact heating of Titan also seems possible.

It is interesting to note that, when the Sun enters it red giant phase, Titan will be in the approximate temperature regime that Earth is in now (Khare et al. 1986). Perhaps if bacterial spores are planted on Titan, either accidentally or purposefully, they could eventually give rise to a new evolutionary sequence of life when Titan becomes warmer. This assumes that terrestrial spores could remain viable in the current deepfreeze environment of Titan for billions of years. We can only speculate about whether or not this is possible.

\section{Atmospheres of the Outer Planets}

A discussion of possible ecological niches in the atmosphere of Jupiter has been made by Sagan and Salpeter (1976). Also, constraints on bacterial growth in the atmospheres of the outer planets have been discussed by Margulis et al. (1977) and by Chang and MacElroy (1977). For growth, bacteria need liquid water, a moderate temperature, and access to nutrients and trace minerals. Drops of liquid water in the water cloud regions of the giant planets offer a possible niche for bacterial growth although, due to settling and atmospheric mixing, an individual cloud drop where bacteria could grow would evaporate in a short period. Nevertheless, Stoker and Boston (1984) argued that steady-state populations of organisms could be sustained in the transient environment of Jupiter's water clouds if enough nutrients were available to sustain growth.

Tholins may be produced in the stratospheres of the giant planets by ultraviolet light (Khare et al. 1978), by magnetospheric charged particle leakage (Khare et al. 1981) and by lightning in the convective tropospheres (Bar-Nun et al. 1984). However, D. M. Hunten (personal communication, 1985) has considered whether tholins and other organics produced in the Jovian atmosphere could provide nutrients to sustain bacterial growth when dissolved in water cloud drops. He concluded that, even if the entire steady-state population of organics in the water cloud region were dissolved in the cloud drops, the mean amount of carbon in a single drop would be several orders of magnitude less than the amount needed to 
produce one bacterium. In addition, a bacterium confined to a water drop cannot readily collect more drops to obtain more carbon. Thus, it seems impossible for bacteria in the Jovian water cloud drops to use tholins as a growth substrate.

\section{Icy Satellites}

Liquid water, a prerequisite for the growth of terrestrial organisms, may be found in the interiors of some icy satellites. Tidal and radiogenic heating may maintain a liquid water ocean beneath a relatively thin ice crust on Europa (Squyres et al. 1983) and possibly on the Saturnian satellite Enceladus and the Uranian satellite Ariel (Reynolds et al. 1987). Photosynthetic organisms might be able to live beneath the ice on Europa (Reynolds et al. 1983) but growth would be limited by the transient availability of sunlight during periods when the ice fractures.

As an alternative to the scant sunlight penetrating an ice crust, tholins could provide an energy source for bacterial growth in the interiors of icy satellites. Since methane, ammonia, and water are components of the outer planets, they may be components of their satellites as well. Organic compounds have been synthesized at extremely low temperatures in an icy mixture of water, ammonia, and methane at $77^{\circ} \mathrm{K}$ (Oro 1963). When ices containing $\mathrm{CH}_{4}$ are bombarded by charged particles, a low-density, dark organic material is produced (Calcagno et al. 1985, Thompson et al. 1987). Thus, tholins may be produced by cosmic ray bombardment of icy satellites. Tholins could be cycled into the interiors of the satellites by meteoritic impact and redistribution of the ice due to tidal stress (Cassen et al. 1979). Thus, the interiors of outer planetary icy satellites are a possible niche where bacteria could live on tholins.

\section{Comets and Asteroids}

Among a wide variety of other organic compounds, amino acids are a known component of carbonaceous chondrites, constituting $\sim 10 \%$ of the organics and $\geq 0.1 \%$ of the mass (Cronin et al. 1987). This organic mixture shows some similarity to tholins and to terrestrial kerogens and, when liquid water is available, may provide a growth medium for microorganisms in a manner similar to that described in the present paper. Such experiments should be attempted. There is now a range of more direct evidence (Huebner 1987, Kissel and Kruger 1987, Chyba and Sagan 1987) that complex organic molecules are abundant on the surfaces and interiors of comets. However, even though these bodies are potentially richly endowed with nutrients, they should lack even transient liquid water. This will preclude the growth of terrestrial microbes on these bodies.

\section{SUMMARY AND CONCLUSIONS}

The key result of this study is that a wide variety of heterotrophic soil bacteria are able to metabolize tholin as a sole source of carbon. The tholin-using bacteria identified include strict aerobes, strict anaerobes, and facultative anaerobes. They represent 12 distinct genera and constitute $2.4 \%$ of the total identifiable population of soil bacteria. Thus, this study unambiguously proves that organic compounds created in chemical synthesis experiments can support microbial life.

The striking thing about the results of these experiments is the variety and number of microorganisms that can utilize tholin. The apparent palatability of tholin suggests that it could have been involved in supporting the first organisms if, as many believe, they were heterotrophs.

In addition, the fact that tholins can be metabolized by such a wide range of soil microbes, even under anaerobic conditions, indicates that the presence of these compounds should be taken into account when evaluating the potential for contaminating solar system environments with spacecraft probes. We have presented a brief analysis of the potential for microbial growth in planetary environments where tholins may be present. However, a detailed "environmen- 
tal impact" study of the possible niches for microbial growth should be undertaken for candidate objects before deciding to send an unsterilized probe there. Finally, any planetary environment which could support terrestrial bacteria is also a good candidate for exobiology experiments to search for in situ life forms.

\section{ACKNOWLEDGMENTS}

We thank K. Zahnle and C. P. McKay for helpful comments and reviews of a preliminary draft of the manuscript. We thank Robert Sherwood for assistance with amino acid analysis and Ted Thannhauser for helpful discussion. This work was supported in part by NASA Grant NGR 33-010-101.

\section{REFERENCES}

Bar-Nun, A., N. Noy, ANd M. Podolak 1984. An upper limit to the abundance of lightning-produced amino acids in the Jovian water clouds. Icarus 59, 162-168.

Boston, P. J., ANd C. R. Stoker 1982. Microbial metabolism of organic molecules produced by chemical synthesis in a reducing atmosphere: Implications for the origin of life on Earth. Lunar Planet. Inst. Tech. Rep. 83-10, 31-39.

Buchannan, R. E., AND GibBons, N. E. (Eds.) 1974. Bergey's Manual of Determinative Bacteriology, 8th ed. Williams \& Wilkins, Baltimore.

Calcagno, L., G. Foti, L. Torrisı, and G. StrazzULLA 1985. Fluff layers obtained by ion bombardment of frozen methane: Experiments and applications to Saturn and Uranian satillites. Icarus 63, 31-38.

Cassen, P., R. T. Reynolds, and S. J. Peale 1979. Is there liquid water on Europa? Geophys. Res. Lett. 6, 731-734.

Chang, S., D. Desmarais, R. Mack, S. L. Miller, and G. Strathear 1984. Prebiotic organic synthesis and the origin of life. In Earth's Earliest Biosphere: It's Origin and Evolution. (J. W. Schopf, Ed.). Princeton Univ. Press, Princeton, NJ.

Chang, S., and R. D. MacElroy 1977. Possible nutrients and energy sources available to contaminating terrestrial organisms on Jupiter. Life Sci. Space Res. 15, 89-93.

Chyba, C., AND C. Sagan 1987. Infrared emission by organic grains in the coma of Halley's comet. Nature 330, 350-353.

Cohen, S. A., B. A. Bidlingmeyer, And T. L. TARVIN 1986. PITC derivatives in amino acid analysis. Nature 320, 769-770.

CostiLow, R. N. 1981. Biophysical factors in growth. In Manual of Methods for General Bacteriology. ( $\mathrm{P}$. Gerhardt, Ed.). American Society for Microbiology, Washington, DC.
Cronin, J. R., G. U. Yuen, and S. Pizzarello 1987. Organic chemistry of carbonaceous meteorites. In NASA Space Life Sciences Symposium, Washington DC, June 21-26, 1987.

DAY, W. 1979. Genesis on Planet Earth: The Search for Life's Beginnings. House of Talos, East Lansing, MI.

Funk, H. B., AND T. A. Krulwich 1964. Preparation of clear silica gels that can be streaked. $J$. Bacteriol. 88, 1200-1201.

Gabel, N. 1977. Chemical evolution: A terrestrial reassessment. In Progress in Molecular and Subcellular Biology (F. E. Hahn, Ed.), Vol. 5, pp. 145-172. Springer, Heidelberg.

GerhaRDT, P. 1981. Manual of Methods for General Bacteriology. American Society for Microbiology, Washington, DC.

Haldane, J. B. S. 1929. The origin of life. Reprinted in Science and Human Life, p. 149. Harper Bros., New York, 1933.

HAYES, J. M. 1967. Organic constituents of meteorites-A review. Geochem. Cosmochem. Acta 31, 1395-1440.

HuEBNER, W. F. 1987. First polymer in space identified in comet Halley. Science 237, 628-630.

Keller, H. U., C. Arpigny, C. Barbieri, R. Bonnet, S. Cazes, M. Coradini, C. Cosmovici, W. Delamere, W. Huebner, D. Hughes, C. Jamar, D. Malaise, H. Reitsema, H. SchmidT, W. SchNidt, P. Seige, F. Whipple, and K. Wilhelm 1986. First Halley multicolor camera imaging results from Giotto. Nature 321, 320-326.

KHARE, B. N., AND C. SAGAN 1973. Red clouds in reducing atmospheres. Icarus 20, 311-321.

Khare, B. N., C. Sagan, E. L. Bandurski, and B. NAGY. 1978. Ultraviolet photoproduced organic solids synthesized under simulated Jovian conditions: Molecular analysis. Science 199, 1199-1201.

Khare, B. N., C. Sagan, H. Ogino, B. Nagy, C. Er, K. H. Schram, and E. T. Arakawa 1986. Amino acids derived from Titan tholins. Icarus 68, 176-184.

Khare, B. N., C. Sagan, W. R. Thompson, E. T. ArakAwa, AND P. VOTAw 1987. Solid hydrocarbon aerosols produced in simulated Uranian and Neptunian stratospheres. J. Geophys. Res. 92, 15067-15082.

Khare, B. N., C. Sagan, W. R. Thompson, E. T. arakawa, F. Wuits, T. A. Callcott, M. W. Williams, S. Shrader, H. Ogino, T. O. Willingham, AND B. NAGY 1984. The organic aerosols of Titan. Adv. Space Res. 4, 59-68.

Khare, B. N., C. Sagan, J. E. Zumberge, D. S. Sklarew, AND B. Nagy 1981. Organic solids produced by electrical discharge in reducing atmosphere: Tholin molecular analysis. Icarus 48, 290-287.

Kissel, J., AND F. R. Kruger 1987. The organic component in dust from Comet Halley as measured by the 
PUMA mass spectrometer on board Vega 1. Nature 326, $755-760$.

KocH, A. L. 1981. Growth measurement. In Manual of Methods for General Bacteriology (P. Gerhardt, Ed.). American Society for Microbiology, Washington, DC.

Krieg, N., AND P. Gerhardt 1981. Solid Culture. In Manual of Methods for General Bacteriology ( $\mathrm{P}$. Gerhardt, Ed.). American Society for Microbiology, Washington, DC.

Lindal, G. F., G. E. Wood, H. B. Hotz, D. N. Sweetnam, V. R. Eshelman, and G. L. Tyler 1983. The atmosphere of Titan: An analysis of the Voyager 1 radio occultation measurements. Icarus 53, 348-363.

MARgulis, L. 1981. Symbiosis and Cell Evolution: Life and its Environment on the Early Earth. Freeman, San Francisco.

Margulis, L., H. O. Halvorson, J. Lewis, and A. G. W. Cameron 1977. Limitations to growth of microorganisms on Uranus, Neptune and Titan. Icarus 30, 793-808.

Mckay, C. P., J. B. Pollack, and R. Courtin 1989. The thermal structure of Titan's atmosphere. Icarus 80, 23-53.

Miller, S. L. 1953. A production of amino acids under possible primitive Earth conditions. Science 117, 528-529.

Miller, S. L. 1955. Production of some organic compounds under possible primitive Earth conditions. $J$. Amer. Chem. Soc. 77, 2351-2361.

Miller, S. L. 1957. The mechanism of synthesis of amino acids by electrical discharges. Biochim. Biophys. Acta 23, 480-489.

Miller, S. L., AND L. F. Orgel 1974. The Origins of Life on Earth. Prentice-Hall, Englewood Cliffs, NJ.

Mitchell, D. L., R. P. LiN, K. A. Anderson, C. W. Carlson, D. W. Curtis, A Korth, H. Reme, J. A. Sauvaud, C. D'Uston, and D. A. Mendis 1987. Evidence for chain molecules enriched in carbon, hydrogen, and oxygen in Comet Halley. Science 237, 626-628.

OPARIN, A. I. 1924. The origin of life. Reprinted in The Origin of Life (J. D. Bernal, Ed.) World Publishing Co., New York, 1967.

Oro, J. 1963. Studies in experimental cosmochemistry. Ann. N.Y. Acad. Sci. 108, 464-481.

Oyama, V. I. 1972. Search for biogenic structures and viable organisms in lunar samples: A review. Space Life Sci. 3, 377-382.

Reynolds, R. T., C. P. MCKay, and J. F. Kasting 1987. Europa, tidally heated oceans and habitable zones around giant planets. Adv. Space Res. 7, $125-132$

Reynolds, R. T., S. W. Squyres, D. S. Colburn, AND C. P. MCKAY 1983. On the habitability of Europa. Icarus 56, 246-254.

SAGAN, C., AND B. N. KHARE 1971. Long wavelength ultraviolet photoproduction of amino acids in the primitive Earth. Science 173, 417-520.

Sagan, C., AND B. N. Khare 1979. Tholins: Organic chemistry of interstellar grains and gas. Nature 277 , 102-107.

Sagan, C., B. N. Khare, and J. S. Lewis 1984a. Organic matter in the Saturn system. In Saturn (T. Gehrels and M. S. Mathews, Eds.), pp. 788-807. Univ. of Arizona Press, Tucson.

Sagan, C., and E. E. Salpeter 1976. Particles, environments, and possible ecologies in the Jovian atmosphere. Astrophys. J. Suppl. Ser. 32, 737-755.

Sagan, C., And W. R. Thompson 1984. Production and condensation of organic gases in the atmosphere of Titan. Icarus 59, 133-161.

Sagan, C., W. R. Thompson, B. N. Khare, and E. T. ARAKAwA 1984b. Titan: Multiple light scattering by organic aerosols and condensates. Bull. Amer. Astron. Soc. 16, 665.

Sagan, C., W. R. Thompson, S. Souyres, and B. N. KHARE 1985. Photometry, multiple light scattering and lab simulations: Constraints on the structure of Titan's haze/cloud. Bull. Amer. Astron. Soc. 17, 700.

SCHOPF, J. W., AND M. R. WAlter 1984. Archean microfossils: New evidence of ancient microbes. In Earth's Earliest Biosphere: It's Origin and Evolution. Princeton Univ. Press, Princeton, NJ.

Stoker, C., AND P. J. Boston 1984. Energy sources, nutrients and environmental limits to growth of contaminating terrestrial microorganisms on Jupiter. Bull. Amer. Astron. Soc. 16, 694.

Stribling, R., AND S. L. Miller 1987. Energy yields for hydrogen cyanide and formaldehyde synthesis: The HCN and amino acid concentrations in the primitive ocean. Origins Life 17, 261-273.

Squyres, S. W., R. T. Reynolds, P. M. Cassen, and S. J. PEALE 1983. Liquid water and active resurfacing on Europa. Nature 301, 225-226.

Squyres, S. W., W. R. Thompson, and C. Sagan 1984. Voyager imaging observations of Titan's atmosphere: I. Disk-resolved photometric properties. Bull. Amer. Astron. Soc. 16, 664.

Thompson, W. R., B. G. J. P. T. Murray, B. N. KHARE, AND C. SAGAN 1987. Coloration and darkening of methane clathrate and other ices by charged particle irradiation: Applications to the outer solar system. J. Geophys. Res. 92, A13, 14933-14948.

Thompson, W. R., and C. SAGan 1984. Titan: Farinfrared and microwave remote sensing of methane clouds and organic haze. Icarus 60, 236-259.

Thompson, W. R., S. W. SquYres, and C. SAGan 1984. Voyager imaging observations of Titan's atmosphere. II. Variation of particle properties with altitude and latitude. Bull. Amer. Astron. Soc. 16, 664.

Wetherill, G. W. 1977. Evolution of the Earth's planetesimal swarm subsequent to the formation of the Earth and Moon. Proc. Lunar Sci. Conf. 8th, 1-16. 